\title{
Risk factors associated with atrial fibrillation after noncardiac thoracic surgery: Analysis of $\mathbf{2 5 8 8}$ patients
}

Ara A. Vaporciyan, MD

Arlene M. Correa, PhD

David C. Rice, MD

Jack A. Roth, MD

W. R. Smythe, MD

Stephen G. Swisher, MD

Garrett L. Walsh, MD

Joe B. Putnam, Jr, MD

See related editorial on page 629.
From the Department of Thoracic and Cardiovascular Surgery, The University of Texas M. D. Anderson Cancer Center, Houston, Tex.

Received for publication May 1, 2003; revisions requested June 23, 2003; revisions received July 14, 2003; accepted for publication July 31, 2003.

Address for reprints: Ara A. Vaporciyan, MD, M. D. Anderson Cancer Center, 1515 Holcombe Blvd, Box 445, Houston, TX 77030 (E-mail: avaporci@ mdanderson.org).

J Thorac Cardiovasc Surg 2004;127:779-86 $0022-5223 / \$ 30.00$

Copyright $\odot 2004$ by The American Association for Thoracic Surgery

doi:10.1016/j.jtcvs.2003.07.011
Objective: The purpose of this study was to identify risk factors associated with the onset of atrial fibrillation after thoracic surgery to allow more targeted interventions in patients with the highest risk.

Methods: A comprehensive prospective database was used to identify patients undergoing major thoracic surgery from January 1, 1998, through December 31, 2002. Data collection was performed at point of contact: at preoperative evaluation, the time of the operation, discharge, and postoperative visits. All patients undergoing resection of a lung, the esophagus, the chest wall, or a mediastinal mass were included in this study. Univariate and multivariate analyses of factors associated with the development of atrial fibrillation were analyzed.

Results: There were 2588 patients who met the inclusion criteria. The overall incidence of atrial fibrillation was $12.3 \%(\mathrm{n}=319)$. Categories of disease were primary lung cancer, pulmonary metastasis, esophageal cancer, intrathoracic metastasis, benign lung disease, other mediastinal tumors, mesothelioma, chest wall tumors, benign esophagus, and "other." Patients with atrial fibrillation had increased mean lengths of hospital stay, mortality rates, and mean hospital charges. Univariate analysis evaluated age, sex, disease category, comorbidities, preoperative therapy, and procedure, and significant variables were entered into the multivariate analysis. Significant variables (relative risk; 95\% confidence interval) in the multivariate analysis were male sex $(1.72 ; 1.29-2.28)$, age 50 to 59 years $(1.70 ; 1.01-2.88)$, age 60 to 69 years $(4.49 ; 2.79-7.22)$, age 70 years or greater $(5.30 ; 3.28-8.59)$, history of congestive heart failure $(2.51 ; 1.06-6.24)$, history of arrhythmias $(1.92 ; 1.22$ $3.02)$, history of peripheral vascular disease $(1.65 ; 0.93-2.92)$, resection of mediastinal tumor or thymectomy $(2.36$; 0.95-5.88), lobectomy $(3.89 ; 2.19-6.91)$, bilobectomy $(7.16 ; 3.02-16.96)$, pneumonectomy $(8.91 ; 4.59-17.28)$, esophagectomy (2.95; 1.55-5.62), and intraoperative transfusions (1.39; 0.98-1.98).

Conclusions: The significant variables identified by means of multivariate analysis were associated with the occurrence of atrial fibrillation. Preventive therapies in selected populations might reduce the incidence of atrial fibrillation.

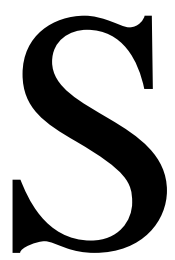

ince initially reported by Bailey and Betts ${ }^{1}$ in 1943, supraventricular tachyrhythmias, particularly atrial fibrillation $(\mathrm{AF})$, have remained one of the most frequent complications that occur after noncardiac thoracic surgery. The occurrence of AF is associated with substantial morbidity, such as increased hospital stay, risk of stroke, postoperative mortality, and significant increases in cost. ${ }^{2-6}$ Efforts to prevent AF have included multiple pharmacologic attempts at prophylaxis, with partial 
success. ${ }^{7-10}$ In addition, new implantable cardioversion techniques are becoming available. ${ }^{11}$ These medications and cardioversion techniques involve some risk and increase costs. Therefore identification of all high-risk populations will allow targeted use and hence more cost-effective and successful application of these methods.

A number of attempts at identifying risk factors for postoperative AF have been made., ${ }^{2,5,12-16}$ These studies have identified age and extent of pulmonary resection as apparent risk factors. However, these studies have examined small numbers of patients or specific groups of patients, such as those undergoing selected surgical procedures or with a specific diagnosis. The applicability of these findings to all patients encountered in a general noncardiac thoracic surgery practice is limited. The relative contributions of chest wall resection, mediastinal tumor resection, metastasectomy, and esophagectomy to the risk of AF are less clearly understood. A more comprehensive assessment of the risk of $\mathrm{AF}$ in all patients undergoing noncardiac thoracic surgery could determine the roles that these events play. The purpose of this study was to identify preoperative and intraoperative factors that are associated with an increased risk of postoperative $\mathrm{AF}$ in patients undergoing noncardiac thoracic surgery.

\section{Methods}

Patients were selected from a comprehensive, prospective database initiated by our department in January 1998 that includes all patients undergoing major thoracic surgery at The University of Texas M. D. Anderson Cancer Center. Physicians, physician assistants, and nurse extenders involved in patient care collect data at point of contact, which is defined as the following: at the completion of the preoperative evaluation, at the time of the operation, on the day of discharge, and at every postoperative outpatient encounter. The database is part of our department's quality-improvement program. Although comprehensive, it was not established for the specific goal of identifying risk factors associated with the development of AF but rather as a means of investigating a wide variety of questions. Therefore this constitutes a retrospective review. However, the prospective data collection should minimize the biases and errors associated with retrospective data collection. The use of this database for clinical research has been approved by our institutional review board.

All patients, regardless of diagnosis, who underwent resection of the lung, the esophagus, the chest wall, or a mediastinal mass from January 1, 1998, through December 31, 2002, were included in this analysis. Information was recorded in the database about demographics, comorbidity, medical and surgical histories, preoperative functional testing, operative details, postoperative events, and long-term symptomatic and oncologic outcomes. During this 4-year period, the database was modified by the addition of further data-entry fields to collect more detailed information about each patient. Consequently, some of the patients who were enrolled early in the database had incomplete data relative to more recently entered patients. Only those data that were collected throughout the entire 4-year study period were included in the analysis.
The demographic data that we analyzed were patient age, sex, and category of disease. Preoperative and perioperative factors examined were weight loss, neoadjuvant therapy, smoking history, timing of smoking cessation relative to the operation, alcohol use (defined as $\geq 4 \mathrm{oz} / \mathrm{d}$ or its equivalent), hypertension, congestive heart failure, angina, prior myocardial infarction, arrhythmia, diabetes, peripheral vascular disease, chronic obstructive pulmonary disease (COPD; defined as a disease requiring chronic bronchodilator use), prior cardiothoracic surgery, prior cardiac surgery, prior thoracotomy, procedure performed, mediastinal lymph node dissection, and intraoperative transfusions (defined as the use of any blood products intraoperatively).

All patients had continuous telemetric monitoring of electrocardiography and oxygen saturation for at least the first 72 hours after resection. No routine prophylaxis for AF was in place during the study period, with the exception of a small number of patients undergoing extrapleural pneumonectomy. To identify clinically relevant episodes of AF or atrial flutter, our database definition of $\mathrm{AF}$ is a sustained or repetitive electrocardiographically documented AF or atrial flutter that requires initiation of antiarrhythmic therapy. Data on 30-day mortality rates, length of hospital stay, and hospital charges were also collected.

Statistical analysis consisted of univariate analysis of all variables. All variables were treated as categoric. Variables with a $P$ value of less than .25 were entered into a multivariate logistic regression model. A stepwise backward elimination using the likelihood ratio test with elimination defined by a $P$ value of .1 or greater was performed. For variables that contained multiple categories, such as the procedure performed, a reference category was chosen to perform the multivariate analysis.

\section{Results}

There were 2588 patients available for analysis. The demographic data and the preoperative diagnoses are shown in Table 1. Primary lung cancer, pulmonary metastasis, and primary esophageal cancer accounted for 1988 (77\%) of the 2588 cases. The 88 unspecified diagnoses included predominantly local recurrences of lung and esophageal cancer and primary pulmonary sarcomas.

The procedures performed are shown in Table 2. Lobectomy represented $33 \%$ of the procedures performed; multiple-wedge resections of 2 to 9 nodules, esophagectomy, and single-wedge resections accounted for $42 \%$. The remaining procedures were chest wall or sternal resection, pneumonectomy, mediastinal tumor resection and thymectomy, multiple-wedge resection of more than 9 nodules, segmentectomy, or bilobectomy.

AF occurred in 319 (12.3\%) patients. Factors associated with the development of AF were identified by using univariate and multivariate analyses. The results of the univariate analysis are shown in Table 3 . Highly significant variables $(P \leq .01)$ were age, sex, preoperative diagnosis, weight loss, any smoking history, timing of smoking cessation, hypertension, congestive heart failure, angina, arrhythmias, peripheral vascular disease, COPD, prior thoracotomy, procedure performed, mediastinal node dissection, 
TABLE 1. Demographic data and preoperative diagnoses in 2558 patients undergoing major thoracic surgery

\begin{tabular}{lc}
\hline Patient characteristic and diagnosis & $\begin{array}{c}\text { No. of patients } \\
(\%), \mathbf{n}=\mathbf{2 5 8 8}\end{array}$ \\
\hline Age, y & \\
$<50$ & $690(27)$ \\
$50-59$ & $624(24)$ \\
$60-69$ & $690(27)$ \\
$\geq 70$ & $584(23)$ \\
Sex & \\
Male & $1553(60)$ \\
Female & $1035(40)$ \\
Preoperative diagnosis & \\
Primary lung cancer & $1015(39)$ \\
Metastases, lung parenchyma & $673(26)$ \\
Primary esophageal cancer & $310(12)$ \\
Metastases, other & $143(6)$ \\
Lung, benign & $137(5)$ \\
Other & $88(3)$ \\
Mediastinal tumor & $78(3)$ \\
Pleural disease (mesothelioma) & $65(3)$ \\
Primary chest wall tumors & $65(3)$ \\
Esophagus, benign & $14(1)$ \\
AF & $319(12)$ \\
Mortality (30 d) & $69(3)$ \\
\hline
\end{tabular}

and intraoperative transfusion. The results of the univariate analysis were used to construct the multivariate model. All variables with a $P$ value of .25 or less were included. In addition to the variables that were highly significant in the univariate analysis, neoadjuvant therapy, alcohol use, and prior cardiac surgery fulfilled these criteria for inclusion in the multivariate analysis. Two variables were excluded from entry into the multivariate model. Preoperative diagnosis correlated closely with the procedure performed, and therefore only one of these variables, the procedure performed, was included in the multivariate analysis. For similar reasons, any smoking history was included, but the timing of smoking cessation was not. An additional reason not to include the timing of smoking cessation was that these data were missing for 138 patients. The multiplewedge variable was initially entered into the multivariate model as 2 separate variables: multiple-wedge resections of 2 to 9 nodules and multiple-wedge resections of more than 9 nodules. Neither variable was associated with an increased risk of $\mathrm{AF}$, and therefore the 2 were combined into the single variable of multiple wedges in the final multivariate analysis.

The factors associated with an increased risk of $\mathrm{AF}$ on multivariate analysis were age, male sex, history of congestive heart failure, history of arrhythmias, history of peripheral vascular disease, the procedure performed (specifically, mediastinal tumor resection or thymectomy, lobectomy, bilobectomy, pneumonectomy, and esophagectomy), and any intraoperative transfusion. The results of the multivariate
TABLE 2. Procedures performed on patients undergoing major thoracic surgery

\begin{tabular}{lc}
\hline Procedure performed & $\begin{array}{c}\text { No. of patients } \\
(\%), \mathbf{n}=\mathbf{2 5 8 8}\end{array}$ \\
\hline Lobectomy & 85333 \\
Multiple wedges (2-9 nodules) & 40616 \\
Esophagectomy & 32413 \\
Single wedge & 34713 \\
Chest wall or sternum & 1707 \\
Pneumonectomy & 1686 \\
Mediastinal tumor resection or thymectomy & 1124 \\
Multiple wedges ( $\geq 10$ nodules) & 773 \\
Segmentectomy & 793 \\
Bilobectomy & 522 \\
\hline
\end{tabular}

analysis are shown in Table 4. The variables of age and procedure performed were both found to be significant $(P<$ .01 ) by using the same reference groups as defined for the univariate analysis (age $<50$ years and single-wedge resection, respectively). All age categories were significant predictors of AF compared with age of less than 50 years, and increasing age was associated with increasing risk of AF. With the procedures performed, increasing the volume of lung resected was associated with increased risk of AF. Lobectomy, bilobectomy, and pneumonectomy were associated with progressively increasing relative risk. In addition, esophagectomy was a significant predictor of $\mathrm{AF}$, with a relative risk slightly less than that of a lobectomy. Resection of a mediastinal tumor or thymoma approached significance, with a relative risk similar to that of esophagectomy.

The incidence of AF was not dependent on the esophageal resection technique. Transthoracic (Ivor Lewis) esophagectomy was performed in 148 patients, transhiatal esophagectomy in 118 patients, and 3-field esophagectomy in 54 patients. The AF incidence was $16.2 \%, 18.6 \%$, and $16.7 \%$, respectively $(P=.789)$.

The development of AF after thoracic surgery significantly increased mortality rate $(2.0 \%$ vs $7.5 \%, P<.001)$, length of hospital stay (mean $\pm \mathrm{SD}, 8.2 \pm 11.0$ days vs 16.6 \pm 18.6 days; $P<.001$ ), and hospital charges (mean \pm $\mathrm{SD}, \quad \$ 28,325.98 \pm \$ 40,126.15$ vs $\$ 56,426.57 \pm$ $\$ 88,924.53 ; P<.001)$. When patients without any complications $(\mathrm{n}=1422)$ were compared with patients with only AF $(\mathrm{n}=104)$, there still was a significant increase in hospital cost (mean $\pm \mathrm{SD}, \$ 21,425.38 \pm \$ 19,427.57$ vs $\$ 27,859.38 \pm \$ 12,017.99 ; P=.001)$.

\section{Discussion}

The development of AF after general thoracic surgical procedures remains one of the most frequent complications. This study identified age, male sex, a history of congestive heart failure, arrhythmia or peripheral vascular disease, the procedure performed, and the use of intraoperative transfu- 
TABLE 3. Results of univariate analysis to identify variables associated with AF after major thoracic surgery

\begin{tabular}{|c|c|c|c|c|}
\hline \multirow[b]{2}{*}{ Variable examined } & \multirow[b]{2}{*}{ Total } & \multicolumn{2}{|c|}{ No. of patients } & \multirow[b]{2}{*}{$P$ value } \\
\hline & & with AF & $(\%)$ & \\
\hline Age, y (reference: age <50 y) & & & & $<.01$ \\
\hline$<50$ & 690 & 244 & & \\
\hline $50-59$ & 624 & 45 & 7 & $<.01$ \\
\hline $60-69$ & 690 & 123 & 18 & $<.01$ \\
\hline$\geq 70$ & 584 & 127 & 22 & $<.01$ \\
\hline Sex & & & & $<.01$ \\
\hline Male & 1553 & 231 & 15 & \\
\hline Female & 1035 & 88 & 8 & \\
\hline Preoperative diagnosis (reference: lung, benign) & & & & $<.01$ \\
\hline Primary lung cancer & 1015 & 193 & 19 & $<.01$ \\
\hline Metastases, lung parenchyma & 673 & 28 & 4 & .15 \\
\hline Primary esophageal cancer & 310 & 49 & 16 & $<.01$ \\
\hline Metastases, other & 143 & 8 & 6 & .08 \\
\hline Lung, benign & 137 & 2 & 2 & \\
\hline Other (NOS)* & 88 & 8 & 9 & .05 \\
\hline Mediastinum & 78 & 7 & 9 & .02 \\
\hline Pleura (mesothelioma) & 65 & 19 & 29 & $<.01$ \\
\hline Primary chest wall tumors & 65 & 4 & 6 & .09 \\
\hline Esophagus, benign & 14 & 3 & 21 & $<.01$ \\
\hline Weight loss (reference: no weight loss)† & & & & $<.01$ \\
\hline No weight loss & 2207 & 252 & 12 & \\
\hline$<8 \mathrm{~kg}$ & 225 & 45 & 20 & $<.01$ \\
\hline$\geq 8 \mathrm{~kg}$ & 137 & 20 & 15 & .26 \\
\hline Neoadjuvant therapy (reference: no preoperative therapy) & & & & .18 \\
\hline No preoperative therapy & 1698 & 212 & 13 & \\
\hline Chemotherapy & 576 & 60 & 10 & .19 \\
\hline Radiotherapy & 23 & 2 & 9 & .59 \\
\hline Chemotherapy and radiotherapy & 291 & 45 & 16 & .16 \\
\hline Any smoking history & & & & $<.01$ \\
\hline Yes & 1720 & 256 & 15 & \\
\hline No & 868 & 63 & 7 & \\
\hline Timing of smoking cessation (reference: never smoked)‡ & & & & $<.01$ \\
\hline Never smoked & 868 & 63 & 7 & \\
\hline $0-14 \mathrm{~d}$ before the operation & 217 & 17 & 8 & .77 \\
\hline $15 \mathrm{~d}$ to 1 mo before the operation & 156 & 22 & 14 & $<.01$ \\
\hline$>1$ mo to $\leq 12$ mo before the operation & 259 & 46 & 18 & $<.01$ \\
\hline$>12$ mo to $\leq 5$ y before the operation & 610 & 88 & 14 & $<.01$ \\
\hline$>5$ y before the operation & 346 & 74 & 21 & $<.01$ \\
\hline Alcohol use $(\geq 4 \mathrm{oz} / \mathrm{d})$ & & & & .05 \\
\hline Yes & 289 & 46 & 16 & \\
\hline No & 2299 & 273 & 12 & \\
\hline Hypertension & & & & $<.01$ \\
\hline Yes & 734 & 126 & 17 & \\
\hline No & 1854 & 193 & 10 & \\
\hline Congestive heart failure & & & & $<.01$ \\
\hline Yes & 25 & 9 & 36 & \\
\hline No & 2563 & 310 & 12 & \\
\hline Angina & & & $<.01$ & \\
\hline Yes & 40 & 11 & 28 & \\
\hline No & 2548 & 308 & 12 & \\
\hline Prior myocardial infarction & & & & .90 \\
\hline Yes & 102 & 13 & 13 & \\
\hline No & 2486 & 306 & 12 & \\
\hline Arrhythmias & & & & $<.01$ \\
\hline Yes & 117 & 35 & 30 & \\
\hline No & 2471 & 284 & 11 & \\
\hline Diabetes & & & & .35 \\
\hline Yes & 194 & 28 & 14 & \\
\hline No & 2394 & 291 & 12 & \\
\hline
\end{tabular}


TABLE 3. Continued

\begin{tabular}{|c|c|c|c|c|}
\hline \multirow[b]{2}{*}{ Variable examined } & \multirow[b]{2}{*}{ Total } & \multicolumn{2}{|c|}{ No. of patients } & \multirow[b]{2}{*}{$P$ value } \\
\hline & & With AF & $(\%)$ & \\
\hline Peripheral vascular disease & & & & $<.01$ \\
\hline Yes & 69 & 20 & 29 & \\
\hline No & 2519 & 299 & 12 & \\
\hline COPD & & & & .01 \\
\hline Yes & 250 & 43 & 17 & \\
\hline No & 2338 & 276 & 12 & \\
\hline Prior cardiothoracic surgery & & & & .38 \\
\hline Yes & 426 & 47 & 11 & \\
\hline No & 2162 & 272 & 13 & \\
\hline Prior cardiac surgery & & & & .02 \\
\hline Yes & 89 & 18 & 20 & \\
\hline No & 2499 & 301 & 12 & \\
\hline Prior thoracotomy & & & & $<.01$ \\
\hline Yes & 308 & 23 & 7 & \\
\hline No & 2280 & 296 & 13 & \\
\hline Procedure performed (reference: single wedge) & & & & $<.01$ \\
\hline Single wedge & 347 & 14 & 4 & \\
\hline Multiple wedges & 483 & 15 & 3 & .47 \\
\hline Chest wall or sternum & 170 & 6 & 4 & .78 \\
\hline Mediastinal tumor resection or thymectomy & 112 & 9 & 8 & .10 \\
\hline Segmentectomy & 79 & 6 & 8 & .18 \\
\hline Lobectomy & 853 & 151 & 18 & $<.01$ \\
\hline Bilobectomy & 52 & 13 & 25 & $<.01$ \\
\hline Pneumonectomy & 168 & 50 & 30 & $<.01$ \\
\hline Esophagectomy & 324 & 55 & 17 & $<.01$ \\
\hline Mediastinal lymph node dissection & & & & $<.01$ \\
\hline Yes & 589 & 109 & 19 & \\
\hline No & 1999 & 210 & 11 & \\
\hline Any intraoperative transfusion & & & & $<.01$ \\
\hline Yes & 346 & 67 & 19 & \\
\hline No & 2242 & 252 & 11 & \\
\hline
\end{tabular}

*0ther includes patients with locally recurrent lung and esophageal cancer or primary pulmonary sarcomas.

tData on 19 patients were missing, and therefore the total number analyzed was 2569 .

‡Data on 132 patients were missing, and therefore the total number analyzed was 2456 .

sion as predictors of postoperative AF. The patients evaluated in this study represented a broad spectrum of general thoracic surgical oncology patients. A wide variety of diagnoses and procedures were examined, which allows generalization of these results to other general thoracic practices. Our $12.3 \%$ overall incidence of AF is similar to that in other published reports. ${ }^{12-16}$ In addition, the associations of AF with increased hospital stay and increased 30-day mortality are also consistent with other published reports. ${ }^{4,5,12,17}$

Previous attempts to identify factors associated with the development of AF after noncardiac thoracic surgery have been performed. Although most have examined specific subgroups of patients undergoing pulmonary resection, primarily for lung cancer ${ }^{14-16,18}$ or esophagectomy, ${ }^{2}$ a few investigators have examined a broader population of patients similar to our patient population. ${ }^{5,12,13}$ The most frequent risk factors identified in these studies have been increasing age and extent of pulmonary resection. Other reported factors have included a history of hypertension, ischemic changes on electrocardiography, cardiac enlargement, prior myocardial infarction, congestive heart failure, mediastinal lymph node dissection, intraoperative cardiac arrest, and need for repeat thoracotomy.

The association between age and AF was closely examined by Amar and colleagues. ${ }^{12}$ In their analysis of 527 patients undergoing lobectomy, pneumonectomy, or esophagectomy over a 10 -year period, they found incidences of AF to be $4 \%, 8 \%, 14 \%$, and $25 \%$ in patients younger than 50 years, 50 to 59 years, 60 to 69 years, and 70 or more years of age, respectively. These findings are very similar to those of our univariate analysis and support the association of increasing incidence of AF with increasing age.

The association between the extent of pulmonary resection and AF has been identified by a number of investigators. Asamura and associates ${ }^{13}$ examined 267 nonesophageal operations in a 1-year period and reported increasing incidence of AF with increasing volume of lung resected. Likewise, other investigators have found the highest inci- 
TABLE 4. Results of multivariate analysis to identify variables associated with AF after major thoracic surgery

\begin{tabular}{lrrr}
\hline Variable & $\begin{array}{c}\text { Relative } \\
\text { risk }\end{array}$ & $\begin{array}{c}\text { Confidence } \\
\text { interval }\end{array}$ & $\boldsymbol{P}$ value \\
\hline Age, y (reference: age $<50 \mathrm{y}$ ) & & & \\
$50-59$ & 1.70 & $1.01-2.88$ & .05 \\
$60-69$ & 4.49 & $2.79-7.22$ & $<.01$ \\
$\geq 70$ & 5.30 & $3.28-8.59$ & $<.01$ \\
Sex & 1.72 & $1.29-2.28$ & $<.01$ \\
Congestive heart failure & 2.51 & $1.01-6.24$ & .05 \\
Arrhythmias & 1.92 & $1.22-3.02$ & $<.01$ \\
Peripheral vascular disease & 1.65 & $0.93-2.92$ & .09 \\
Procedure performed (reference: & & & \\
$\quad$ single wedge) & & & \\
$\quad$ Lobectomy & 3.89 & $2.19-6.91$ & $<.01$ \\
$\quad$ Multiple wedges & 0.87 & $0.41-1.85$ & .72 \\
$\quad$ Esophagectomy & 2.95 & $1.55-5.62$ & .01 \\
$\quad$ Chest wall or sternum & 0.92 & $0.34-2.47$ & .86 \\
$\quad$ Pneumonectomy & 8.91 & $4.59-17.28$ & $<.01$ \\
$\quad$ Mediastinal tumor resection or & & & \\
$\quad$ thymectomy & & & \\
$\quad$ Segmentectomy & 1.57 & $0.57-4.29$ & .38 \\
$\quad$ Bilobectomy & 7.16 & $3.02-16.96$ & $<.01$ \\
Any intraoperative transfusion & 1.39 & $0.98-1.98$ & .07 \\
\hline
\end{tabular}

dence of AF after pneumonectomy. ${ }^{14-16}$ Our analysis had similar findings; in our study, however, it appeared that the manipulation of the hilum might be as important as the total volume of lung resected. This is a likely hypothesis because it has been shown in patients with chronic AF that the pulmonary veins are an important source of ectopic beats that can initiate paroxysms of AF. ${ }^{19}$ Supporting evidence from our analysis includes the similarity between the singlewedge and multiple-wedge groups (neither was associated with an increased risk of AF despite more lung being resected in the multiple-wedge group) and the association of AF with esophagectomy but not with chest wall or sternal resections. However, patients with a large volume $(>9$ wedges) of lung resected during multiple-wedge resections or patients undergoing chest wall or sternal resections represented only $3 \%$ and $7 \%$, respectively, of the total patient population. Repeat analysis with a greater number of patients should be performed.

The association between male sex and AF has not been commonly identified by other investigators, most likely because of the small numbers of patients analyzed. Polanczyk and coworkers ${ }^{5}$ examined 4181 patients undergoing major noncardiac thoracic or abdominal procedures (hospital stay $\geq 2$ days). Their multivariate analysis identified male sex as a predictor of AF, with an odds ratio (odds ratio, $1.3 ; 95 \%$ confidence interval, 1.0 to $1.7 ; P=.04$ ) similar to that seen in our relative risk data. This association might be explained by the effect of sex on immune response. One hypothesis for the cause of postoperative AF is atrial or pulmonary vein inflammation. ${ }^{20}$ After trauma, male patients have an increased proinflammatory immune response compared with that of female patients, ${ }^{21}$ and this might lead to increased AF after surgical trauma.

The association between intraoperative transfusions and AF found in our analysis has not been previously demonstrated. Although it is possible that there are immunologic effects of transfusion that lead to increased arrhythmias, it is more likely that transfusions represent a marker of more complex or difficult dissection.

The association of cardiac disease with AF has been demonstrated inconsistently by other investigators. ${ }^{5,13,15,16}$ The selection criteria imposed by thoracic surgeons might prevent patients with clinically relevant cardiac disease from undergoing surgical intervention. This is certainly demonstrated in our data because patients with congestive heart failure, angina, prior myocardial infarction, arrhythmias, or peripheral vascular disease represented only $1.0 \%$, $1.5 \%, 3.9 \%, 4.5 \%$, and $2.7 \%$, respectively, of all the patients examined. The common occurrence of $\mathrm{AF}$ after cardiac surgery supports the association of cardiac disease with $\mathrm{AF}$ after thoracic surgery. ${ }^{22,23}$ Our study demonstrated associations of congestive heart failure, arrhythmias, and peripheral vascular disease with AF. Both arrhythmias and congestive heart failure have been identified by various investigators. The association of peripheral vascular disease and AF appears novel. Peripheral vascular disease is predominantly an inflammatory process, and therefore the increased risk of AF in these patients, like male sex, might be due to an intrinsic heightened inflammatory response.

The lack of association between hypertension and AF in our analysis is also noteworthy. Other investigators have shown this association, but their analyses were limited to only 598 or 233 patients with lung cancer. ${ }^{15,18}$ Hypertension occurred commonly in our population $(28.4 \%)$ and was associated with a higher incidence of AF by means of univariate analysis; our multivariate model, however, failed to demonstrate any association. The larger patient population along with inclusion of many different diagnoses and procedures in our analysis might have led to this difference.

The presence of COPD, the performance of a mediastinal lymph node dissection, or the use of neoadjuvant chemotherapy, radiotherapy, or combined chemotherapy and radiotherapy was not associated with the development of $\mathrm{AF}$ in our study. Other investigators have found that the association between COPD and AF is inconsistent. ${ }^{24,25}$ The definition of COPD might vary between different authors and might lead to this inconsistency. Our definition was based on the presence or absence of bronchodilator treatment and not strict pulmonary function testing. Unfortunately, data on pulmonary function were inconsistently collected in our database during the 4-year period of this study. Future analysis could allow inclusion of these parameters into our multivariate model. 
Mediastinal node dissection was performed in $22.8 \%$ of the patients in this study, and although it was associated with a higher incidence of AF in the univariate analysis, it was not predictive of AF in the multivariate model. Finally, the use of neoadjuvant chemotherapy, radiotherapy, or combination therapy was not associated with an increased risk of AF. Investigators have shown a decrease in cardiac perfusion and an increased frequency of cardiac symptoms, ischemia, and mortality after left-breast radiation therapy. ${ }^{26-30}$ Our database does not collect information on the dose and ports used during radiation therapy treatment. Further analysis will be performed, with more detailed attention paid to the cardiac radiation therapy dose and its effect on the development of AF.

In conclusion, our analysis of 2588 patients undergoing a variety of general thoracic procedures demonstrated an association of AF with age, male sex, a history of congestive heart failure, arrhythmia, peripheral vascular disease, the procedure performed (specifically mediastinal tumor resection or thymectomy, lobectomy, bilobectomy, pneumonectomy, and esophagectomy), and the use of intraoperative transfusions. These results in this large cohort of patients confirm the findings of a number of different investigators. The identification of patients with a high risk of AF will allow more directed application of pharmacologic and alternative methods of prophylaxis.

\section{References}

1. Bailey C, Betts RH. Cardiac arrhythmias following pneumonectomy. N Engl J Med. 1943;229:356-9.

2. Amar D, Burt ME, Bains MS, Leung DHY. Symptomatic tachydysrhythmias after esophagectomy: incidence and outcome measures. Ann Thorac Surg. 1996;61:1506-9.

3. Amar D, Roistacher N, Burt M, Reinsel RA, Ginsberg RJ, Wilson RS. Clinical and echocardiographic correlates of symptomatic tachydysrhythmias after noncardiac thoracic surgery. Chest. 1995;108:349-54.

4. Harpole DH, Liptay MJ, DeCamp MM Jr, Mentzer SJ, Swanson SJ, Sugarbaker DJ. Prospective analysis of pneumonectomy: risk factors for major morbidity and cardiac dysrhythmias. Ann Thorac Surg. 1996;61:977-82.

5. Polanczyk CA, Goldman L, Marcantonio ER, Orav EJ, Lee TH. Supraventricular arrhythmia in patients having noncardiac surgery: clinical correlates and effect on length of stay. Ann Intern Med. 1998;129:279-85.

6. Taylor GJ, Malik SA, Colliver JA. Usefulness of atrial fibrillation as a predictor of stroke after isolated coronary artery bypass grafting. Am J Cardiol. 1987;60:905-7.

7. Amar D, Roistacher N, Rusch VW, Leung DHY, Ginsburg I, Zhang H, et al. Effects of diltiazem prophylaxis on the incidence and clinical outcome of atrial arrhythmias after thoracic surgery. J Thorac Cardiovasc Surg. 2000;120:790-8.

8. Ritchie AJ, Bowe P, Gibbons JRP. Prophylactic digitalization for thoracotomy: a reassessment. Ann Thorac Surg. 1990;50:86-8.

9. Ritchie AJ, Tolan M, Whiteside M, McGuigan JA, Gibbons JR. Prophylactic digitalization fails to control dysrhythmia in thoracic esophageal operations. Ann Thorac Surg. 1993;55:86-8.

10. Lanza LA, Visbal AI, DeValeria PA, Zinsmeister AR, Diehl NN, Trastek VF. Low-dose oral amiodarone prophylaxis reduces atrial fibrillation after pulmonary resection. Ann Thorac Surg. 2003;75:223-30.

11. Kleine P, Blommaert D, van Nooten G, Blin O, Haisch G, Stoffelen W, et al. Multicenter results of TADpole (TM) heart wire system used to treat postoperative atrial fibrillation. Eur J Cardiothorac Surg. 1999;15:525-6.
12. Amar D, Zhang H, Leung DHY, Roistacher N, Kadish AH. Older age is the strongest predictor of postoperative atrial fibrillation. Anesthesiology. 2002;96:352-6.

13. Asamura H, Naruke T, Tsuchiya R, Goya T, Kondo H, Suemasu K. What are the risk factors for arrhythmias after thoracic operations? A retrospective multivariate analysis of 267 consecutive thoracic operations. J Thorac Cardiovasc Surg. 1993;106:1104-10.

14. Rena O, Papalia E, Oliaro A, Casadio C, Ruffini E, Filosso P, et al. Supraventricular arrhythmias after resection surgery of the lung. Eur J Cardiothorac Surg. 2001;20:688-93.

15. Vonknorring J, Lepantalo M, Lindgren L, Lindfors O. Cardiac arrhythmias and myocardial ischemia after thoracotomy for lung cancer. Ann Thorac Surg. 1992;53:642-7.

16. Dyszkiewicz W, Skrzypczak M. Atrial fibrillation after surgery of the lung: clinical analysis of risk factors. Eur J Cardiothorac Surg. 1998; 13:625-7.

17. Brathwaite D, Weissman C. The new onset of atrial arrhythmias following major noncardiothoracic surgery is associated with increased mortality. Chest. 1998;114:462-8.

18. Cardinale D, Martinoni A, Cipolla CM, Civelli M, Lamantia G, Fiorentini C, et al. Atrial fibrillation after operation for lung cancer: clinical and prognostic significance. Ann Thorac Surg. 1999;68:1827-31.

19. Haissaguerre M, Jais P, Shah DC, Takahashi A, Hocini M, Quiniou G, et al. Spontaneous initiation of atrial fibrillation by ectopic beats originating in the pulmonary veins. N Engl J Med. 1998;339:659-66.

20. Chung MK, Martin DO, Sprecher D, Wazni O, Kanderian A, Carnes CA, et al. C-reactive protein elevation in patients with atrial arrhythmias-inflammatory mechanisms and persistence of atrial fibrillation. Circulation. 2001;104:2886-91.

21. Angele MK, Schwacha MG, Ayala A, Chaudry IH. Effect of gender and sex hormones on immune responses following shock. Shock. 2000;14:81-90.

22. Ellenbogen KA, Dias VC, Plumb VJ, Heywood JT, Mirvis DM. A placebo-controlled trial of continuous intravenous diltiazem infusion for 24-hour heart rate control during atrial fibrillation and atrial flutter: a multicenter study. J Am Coll Cardiol. 1991;18:891-7.

23. Podrid PJ. Prevention of postoperative atrial fibrillation: What is the best approach? J Am Coll Cardiol. 1999;34:340-2.

24. Sekine Y, Kesler KA, Behnia M, Brooks-Brunn J, Sekine E, Brown JW. COPD may increase the incidence of refractory supraventricular arrhythmias following pulmonary resection for non-small cell lung cancer. Chest. 2001;120:1783-90.

25. Krowka MJ, Pairolero PC, Trastek VF, Payne WS, Bernatz PE. Cardiac dysrhythmia following pneumonectomy. Chest. 1987;91:490-5.

26. Hardenbergh P, Munley M, Hu C, Hollis D, Light K, Blazing M, et al. Doxorubicin-based chemotherapy and radiation increase cardiac perfusion changes in patients treated for left-sided breast cancer (abstract). Breast Cancer Res Treat. 2001;69:231.

27. Gyenes G, Fornander T, Carlens P, Glas U, Rutqvist LE. Detection of radiation-induced myocardial damage by technetium-99m sestamibi scintigraphy. Eur J Nucl Med. 1997;24:286-92.

28. Gyenes G, Rutqvist LE, Liedberg A, Fornander T. Long-term cardiac morbidity and mortality in a randomized trial of pre- and postoperative radiation therapy versus surgery alone in primary breast cancer. $R a$ diother Oncol. 1998;48:185-90.

29. Gyenes G. Radiation-induced ischemic heart disease in breast cancer-a review. Acta Oncol. 1998;37:241-6.

30. Gagliardi G, Lax I, Soderstrom S, Gynes G, Rutqvist LE. Predication of excess risk of long-term cardiac mortality after radiotherapy of stage I breast cancer. Radiother Oncol. 1998;46:63-71.

\section{Discussion}

Dr Robert J. Downey (New York, NY). I have just one brief comment. To me, atrial arrhythmias are certainly common, but I am unsure how severe they are. It occurs, in most experience, in about $20 \%$ of patients, but most patients clear their arrhythmia by the time they leave the hospital, and $98 \%$ of patients are reported as having cleared it within 2 months. It also seems to occur in the setting of many other problems quite commonly, meaning that if 
the patient becomes hypoxic with pneumonia, the atrial arrhythmia might occur as a secondary event. So I am unsure of how severe a complication it is.

I have 4 questions, and in the interest of time, I will collapse the first and the third into a single question. A study like this is very much dependent on both the definitions that you use and the practices that are used at your institution. You required echocardiographic evidence for an atrial arrhythmia. That then was acted on, somebody intervened, which would seem to limit the number, lower the report, and perhaps understate the incidence. On the other hand, your practice is that patients are monitored for 72 hours after the operation, which is more than we do, and that would tend to raise the incidence. Can you comment on how your definition has affected the incidence that you report? Also, was there any prophylaxis against arrhythmias used in any of these subgroups that might have lowered the incidence?

Dr Vaporciyan. I will answer the second question first because that is easier. There is no established method of prophylaxis at our institution, except recently for the extrapleural pneumonectomies, in which the incidence has been high. Patients received diltiazem intraoperatively as a continuous infusion, which is continued postoperatively. But that group actually represented a small portion of the total number of patients, and therefore I do not think it had an effect on the incidence of AF.

As far as the definitions, we have a stepdown unit that all of our patients go to, where they are started automatically on a cardiac monitor and an oxygen monitor. Therefore it is standard practice for all our patients to be monitored. Any tachyarrhythmias identified there are followed up with a 12-lead echocardiogram. If a diagnosis of AF with tachyarrhythmia is made, at that point the patients are treated. That is our standard definition of how they become identified.

Dr Downey. The second question is about the cause of atrial arrhythmias. These have been attributed to either trauma to the pulmonary vein and hence to the atrium and also to damage to the sympathovagal fibers. It was interesting that the anatomic resections were associated with a higher incidence, which is what you would expect, but the mediastinal lymph node dissection was not. Do you have any comments on what your data show about the possible causes of patients going into AF?

Dr Vaporciyan. The thought from the data is that the manipulation of the hilum is probably the most important, specifically the pulmonary veins, and that is something we are going to look into in an animal model in the future. Mediastinal node dissection is not done on all patients undergoing lobectomy because we have a high percentage of metastasectomies at our institution, and some of those require anatomic resections without the addition of mediastinal node dissection. Therefore I was able to dissect out mediastinal node dissection separate from the actual procedure performed. The esophagectomies also have manipulation of the hilum and the posterior left atrial wall, and they also lead to that cause as well. The wedge resections and the actual amount of parenchyma removed did not seem to make a difference. We segregated our multiple-wedge resections by low numbers of wedge resections and high numbers of wedge resections, and there were at least 80 or 90 patients who had greater than 10 wedge resections, which would come close to anatomically about a lobectomy of removal of lung parenchyma. Those patients had the same incidence of AF as patients who underwent a single-wedge resection. Therefore I think it is more the manipulation of the hilum than it is the actual lung volume resected or vagal fibers from a mediastinal node dissection.

Dr Downey. My last question has to do with your multivariable analysis. If I understand your data correctly, you are at high risk for development of an atrial arrhythmia if you are male, if you are over 60 years of age, or if you have an operation other than a wedge resection or an isolated chest wall resection. Obviously I think your risk factors are going to have to be brought together. How are you planning to define the highest-risk group of patients within the overall population?

Dr Vaporciyan. We actually looked at the way the model predicts, and despite the fact that we have entered 2600 patients in 32 variables, it is still not as robust a model as it could be. It actually predicts about $25 \%$ or $30 \%$ of the cases at best and usually about $22 \%$ of the cases. Therefore there are obviously a lot of factors that are involved that we were not able to detect, even with 2600 patients enrolled in this analysis. That being said, I think you still can make the comment that patients undergoing pneumonectomy who are male with advanced age have a high risk and should be considered for some sort of prophylactic therapy.

Dr Daniel L. Miller (Atlanta, $G a$ ). It is interesting that as we go back and look at these AF data, there is not a lot of discussion in regard to the onset of $\mathrm{AF}$, which day it occurred, postoperative day number 1 , number 3 , or number 5 . Did you look at that at all to see whether that made a difference in hospital stay, morbidity, and so forth? And the second part of that, you had a correlation with increased mortality, which a lot of studies with AF these days do not. Was it that the patients that were already going down the tubes on day 7 or 8 who had $\mathrm{AF}$, that it was going on in a sequence? If you could comment on both of those, that would be great.

Dr Vaporciyan. The database does not capture such detailed hospital data. Essentially, at the time of discharge, all complications are entered in the database. We do not make a note of when it happened. Just speaking anecdotally from taking care of the patients, it is usually between 24 and 96 hours, about the second hospital day to the fourth hospital day, that they occur.

In reference to the other aspect about how AF usually accompanies other complications, in the article we examined patients with AF as their only complication, looked at the hospital charges of those patients and the hospital stays of those patients, and compared these values with those of the patients who had no other complications. We found that when you exclude all other complications and look at patients who only had AF, there still was a significant increase in cost and length of stay of about $30 \%$ to $50 \%$. We did not look at mortality yet, and we will look at that as well.

Dr David H. Harpole, Jr (Durham, NC). Dr Putnam and his group at M. D. Anderson deserve credit for putting together this very large prospective database to answer some of these questions. This afternoon we have had a very nice presentation on probably the largest series of pneumonectomies in North America and now a nice prospective series looking at complications. The Society of Thoracic Surgeons database general thoracic module is out. If we want to learn more about these complications and ways to treat them, I encourage all of you to participate in this database, and hopefully over the next 10 years we will have a lot more articles coming out in the Association on this subject. 